\title{
A case of sub emergent operation for salvage of severe pancreatic fistula after left hemi colectomy for advanced transverse colon cancer
}

\begin{abstract}
Following an increase in the use of the $\mathrm{GIA}^{\mathrm{TM}}$ (Covidien Co. Ltd.) stapler for treating a pancreatic stump, more preventive techniques for postoperative pancreatic juice leakage have been required. We had one successful case to salvage of severe pancreatic fistula after left hemicolectomy for advanced transverse colon cancer with pancreatic tail invasion. As the result of our proposal technique $<$ the invagination method of pancreaticogastrostomy, grade $\mathrm{C}$ pancreatic fistula immediately recovered. This is simple and effective technique to prevent pancreatic fistula almost completely.
\end{abstract}

Keywords: distal pancreatectomy, pancreatic fistula, invagination method, pancreatic stump, pancreatic tumor, drain amylase

\author{
Special Issue - 2018 \\ Katsura N, Kawai Y \\ Department of Surgery, Misugikai Satoh Hospital, Japan \\ Correspondence: Katsura N, Department of Surgery, \\ Misugikai Satoh Hospital, Yobuhigashimachi Hirakata, Osaka 573- \\ I I24, Japan, Tel +8I-75-983-000 I, Fax +8I-75-97I-1082 \\ Email n-katsura@takedahp.or.jp
}

Received: May 04, 2017 | Published: September 19, 2018
Abbreviations: ISGPD, international study group of pancreatic fistula; CT, computed tomography; POD, post operative day

\section{Introduction}

Since Billlroth first performed distal pancreatectmy in $1884,{ }^{1}$ a lot of researchers have tried to do this operation successfully with reducing the high morbidity and mortality rates. ${ }^{2-4}$ However, unfortunately, they had been unsuccessful, and some surgeons had concluded that the operation should be abandoned. ${ }^{5}$ Furthermore, pancreatic fistula causes various complications such as abscess, hemorrhage, sepsis, ${ }^{6-9}$ and delayed gastric emptying, ${ }^{10}$ and these may result in considerable health care expenditures. ${ }^{11}$ To prevent these complications, various methods have been reported that include a standard hand-sewn suture after main pancreatic duct ligation, ${ }^{12}$ staple closure, ${ }^{13}$ sealing with glue, ${ }^{14}$ use of a seromuscular patch, ${ }^{15}$ or pancreaticoenteric anastomosis. ${ }^{16}$ However, as for now, any of them have never become a standard procedure. We have proposed new technique to prevent pancreatic fistula with invaginating pancreatic stump into stomach. ${ }^{17}$ here, we report a case of subemergent operation for salvage of severe pancreatic fistula after left hemicolectomy for advanced transverse colon cancer invaded to pancreatic tail with our method, and lead to an excellent result.

\section{Case}

A 69-year-old male with complaint of lower abdominal pain and extension. Colon fiber scope was performed and revealed that tumor occupied about $80 \%$ of intra-space of transverse colon (Figure 1). Enhanced CT showed large tumor from transverse colon and suspicious of the invasion to pancreatic tail (Figure 2A) (Figure 2B). At first, colostomy was done, and after patient's condition recovered, left hemicolectomy and small cut of pancreatic tail with bipolar electric knife. As the result, we experienced the grade $\mathrm{C}$ pancreatic fistula (ISGPF). On day 1 , drain amylase was $85,000 \mathrm{IU} / \mathrm{ml}$. Immediately we performed our new technique showing below; after resection of distal pancreas with GIA, without any additional reinforce, to invaginate the stump to the gastric posterior wall with single layer anastomosis using 3-0 absorbable suture (Figure 3A) (Figure 3B). The anastomosis is not complicated, taking about fifteen minutes. After this operation, drain amylase went down to $242 \mathrm{IU} / \mathrm{ml}$. Drain tubes were removed on $3 \mathrm{rd}$ post operative day.

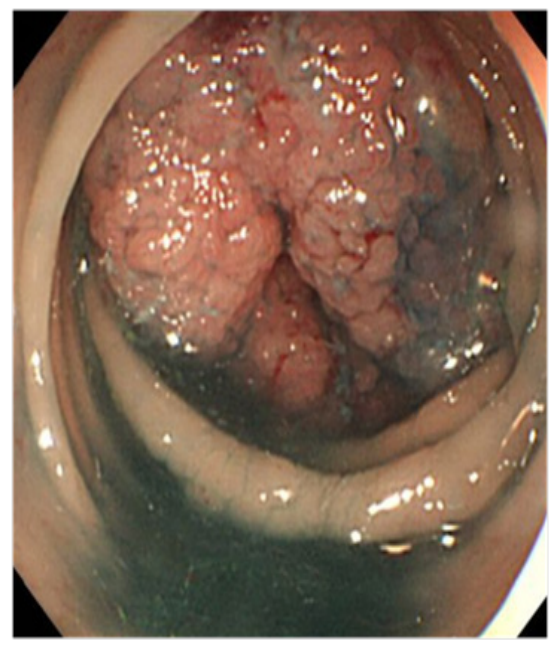

Figure I Colon fiber scope showed advanced tumor which almost occupied the inner space of transverse colon.

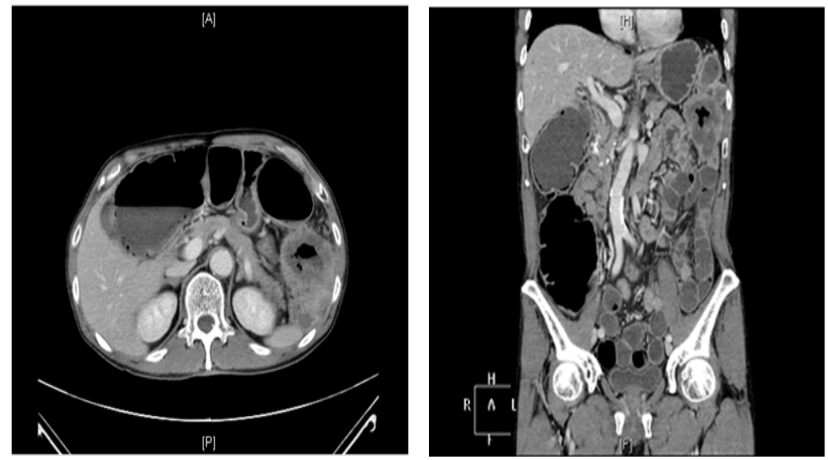

Figure 2 (A \& B) CT scan showed the enhanced colon tumor suspected of invasion to pancreatic tail (white circle). 


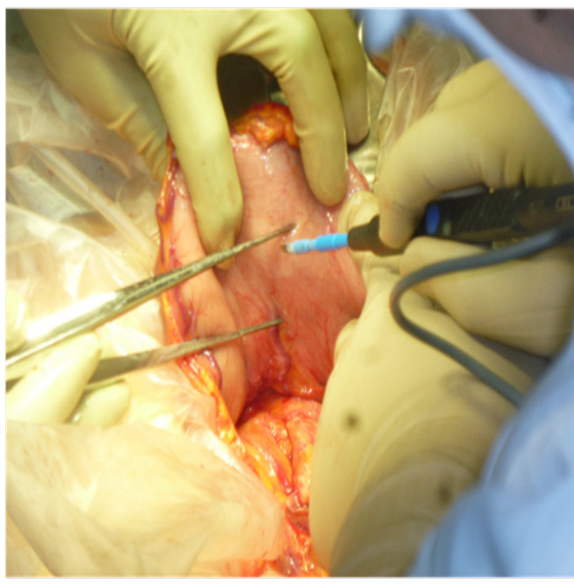

Figure 3(A) Cutting the posterior wall of stomach. The cutting length is $80 \%$ of the width of the pancreatic edge.

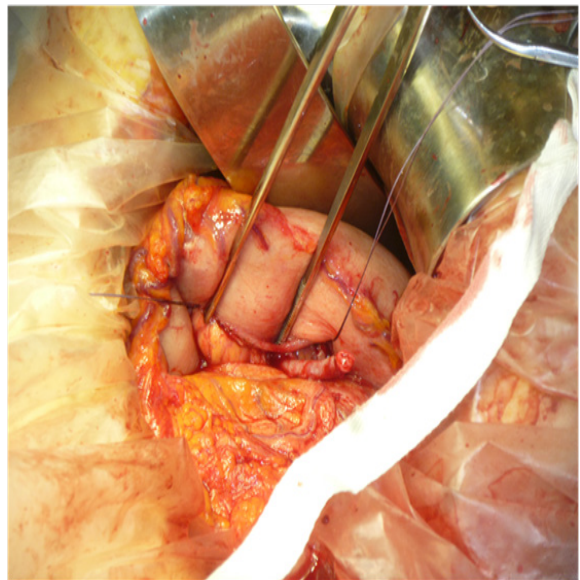

Figure 3(B) Invaginating the pancreatic stump into the stomach.

\section{Discussion}

To prevent pancreatic fistula, various methods have been reported, including a standard hand-sewn suture after main pancreatic duct ligation, ${ }^{12}$ staple closures, ${ }^{13}$ and sealing with glue, ${ }^{14}$ use of a seromuscular patch, ${ }^{15}$ or pancreaticoenteric anastomosis. ${ }^{16}$ Sudo et al. ${ }^{18}$ reported 21 cases performed the distal pancreatectomy with duct-to-mucosa pancreaticogastrostomy for preventing postoperative pancreatic fistula.$^{18}$ Their method lead to no grade B and C pancreatic fistula judged with ISGPS criteria. ${ }^{19,20}$ In their report, they stated two potential factors promoting development of pancreatic fistula after distal pancreatectomy. One is extravasation of pancreatic juice from small branches of the pancreatic duct at the cut surface. The other is the increase in pancreatic ductal pressure associated with increased resistance to outflow of pancreatic juice toward the duodenum owing to contraction of the sphincter of Oddi. Variable closure techniques of the pancreatic stump, including hand-sewn, staples, sealing with fibrin glue, or covering methods, cannot completely seal the small ductal branches. The ligature of the main duct promotes a pressure gradient between the pancreatic duct and duodenum during contraction of the sphincter Oddi, which may lead to pancreatic fistula development from the ductal branches.

In this study, we performed to invaginate the pancreatic stump into the stomach by cutting the posterior wall with anastomosis by single layer. Our procedure is very simple and easy to perform within twenty minutes on the average..$^{17}$ It may be natural to understand that our procedure, invaginating the pancreatic stump into stomach with single layer anastomosis, be easy and take shorter time to complete than the duct-to-mucosa pancreaticogastrostomy with an internal stenting tube and the pancreaticoenteric anastomosis.

In conclusion, the invagination method of the pancreaticogastrostomy may be a simple and effective technique for preventing pancreatic fistula development after distal pancreatectomy. Further clinical trials comparing this method with the other procedures are required to confirm its actual efficacy.

\section{Acknowledgements}

None.

\section{Conflict of interest}

Author declares that there is no conflict of interest.

\section{References}

1. Finney JMT. Resection of the pancreas. Report of a case. Transactions of the American Surgical Associates. 1990;28:315-330.

2. Kleeff J, Diener MK, Z'Graggen K, et al. Distal pancreatectomy: risk factor for surgical failure in 302 consecutive cases. Ann Surg. 2007;245:573-582.

3. Ferrone CR, Warshaw AL, Rattner DW, et al. pancreatic fistula rates after 462 distal pancreatectomies: staplers do not decrease fistula rates. $J$ Gastrointest Surg. 2008;12(10):1691-1698.

4. Kanaebel HP, Diener MK, Wente MN, et al. Systemic review and metaanalysis of technique for closure of the pancreatic remnant after distal pancreatectomy. Br J Surg. 2005;92(5):539-546.

5. Gudjonsson B. Cancer of the pancreas: 50 years of surgery. Cancer. 1987;60(9):2284-2303.

6. Jordan GL. Pancreatic fistula. Am J Surg. 1970;119:200-207.

7. Zinner MJ, Baker RR, Cameron JL. pancreatic cutaneous fistula. Surg Gynecol Obstet. 1974;138:710-712.

8. Fitzgibbons TJ, Yellin AE, Maruyama MM, et al. Management of the transected pancreas following distal pancreatectomy. Surg Gynecol Obstet. 1982;154(2):225-231.

9. Papachristou DN, Fortner JG. Pancreatic fistula complicating pancreatectomy for malignant disease. Br J Surg. 2981;68(4):238-240.

10. Wente MN, Bassi C, Dervenis C, et al. Delayed gastric emptying (DGE) after pancreatic surgery: A suggested definition by the International Study Group of Pancreatic Surgery (IPSGP). Surgery. 2007;142(5):761-768.

11. Rodriguez JR, Germes SS, Pandharipande PV, et al. Implications and cost of pancreatic leak following distal pancreatic resection. Arch Surg. 2006;141(4):361-366.

12. Bilimoria MM, Cormier JN, Mun Y, et al. pancreatic leak after left pancreatectomy is reduced following main pancreatic duct ligation. $\mathrm{Br} J$ Surg. 2003;90(2):190-196.

13. Kajiyama Y, Tsurumaru M, Udagawa H, et al. Quick and simple distal pancreatectomy using the GIA stapler: report of 35 cases. Br J Surg. $1996 ; 83: 1711$

14. Suzuki Y, Kuroda Y, Morita A, et al. Fibrin Glue Sealing for the Prevention of Pancreatic Fistula Following Distal Pancreatectomy. Arch Surg. 1995;130(9):952-955. 
15. Kuroki T, Tajima Y, Tsuneoka N, et al. Gastric Wall-Covering method prevents pancreatic fistula after distal pancreatectomy. HepatoGastroenterology. 2009;56(91-92):877-880.

16. Wagner M, Gloor B, Ambuhl M, et al. Roux-en-Y drainage of the pancreatic stump decreases pancreatic fistula after distal pancreatic resection. J Gastrointest Surg. 2007;11(3):303-308.

17. Katsura N, Kawai Y, Gomi T, et al. Preventing pancreatic fistula after distal pancreatectomy: An invagination method. World J Gastroenterol. 2017;23(8):1507-1512.
18. Sudo T, Murakami Y, Uemura K, et al. distal pancreatectomy with ductto-mucosa pancreaticogastrostomy: a novel technique for preventing post operative pancreatic fistula. Am J Surg. 2011;202(1):77-81.

19. Bassi C, Dervenis C, Butturini G, et al. Postoperative pancreatic fistula: an international study group (ISGPF) definition. Surgery. 2005; 138(1):8-13.

20. Dindo D, Demartines N, Clavien PA. Classification of surgical complications: a new proposal with evaluation in a cohort of 6336 patients and results of a survey. Ann Surg. 2004;240(2):205-213. 